\title{
Rhomboencephalitis due to cocaine-induced bony erosion of skull base
}

Figure 1 Initial brain and cervical spine MRI

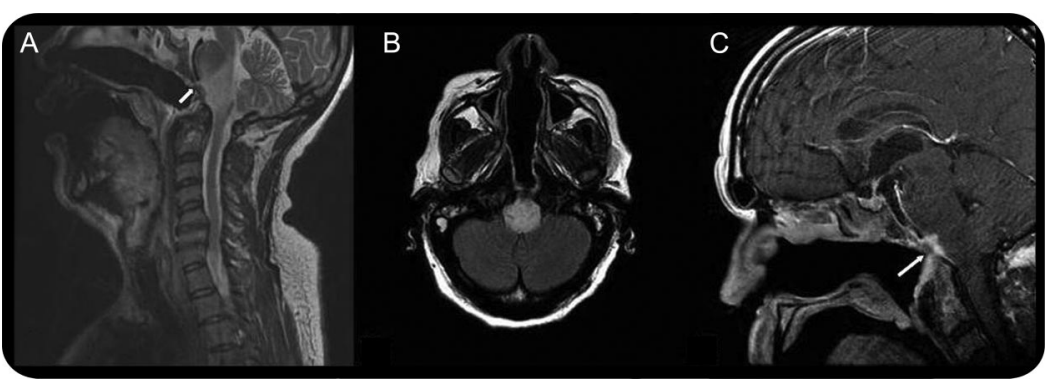

Sagittal T2 (A), axial T2 fluid-attenuated inversion recovery (B), and sagittal T1 with contrast MRI (C) show a large bony defect in the skull base with erosion of the sphenoid sinus walls and perforated nasal septum. There is abnormal T2 hyperintensity and enhancement in the brainstem with clival erosion (arrow where most severe) and marrow enhancement.

\section{Figure 2 Brain MRI after 6 weeks of IV antibiotics}

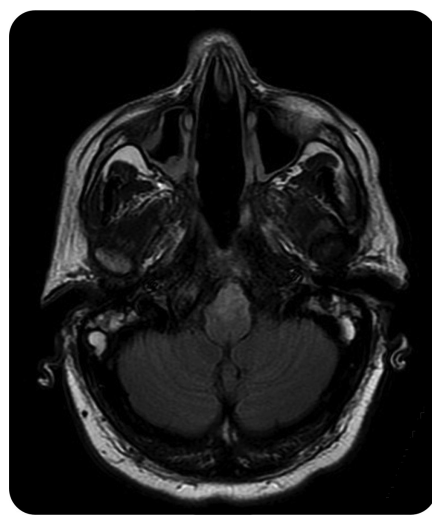

Axial T2 fluid-attenuated inversion recovery MRI of the brain demonstrates decreased T2 fluid-attenuated inversion recovery hyperintensity in the medulla following 6 weeks of IV antibiotics.

A 49-year-old man with 10 years of intranasal cocaine use presented with dysphagia. Neurologic examination demonstrated bilateral sixth nerve palsies. Brain MRI showed erosion of the sphenoid sinus walls and a defect in the skull base; the resulting path between the nasal cavity and brainstem permitted rhomboencephalitis and clival osteomyelitis (figure 1). Clival cultures grew methicillin-resistant Staphylococcus aureus. IV antibiotics were administered and switched to oral after 6 weeks. Repeat MRI showed decreased T2 fluid-attenuated inversion recovery brainstem hyperintensity (figure 2). Antibiotics will be used for at least 1 year; surgical reconstruction of the skull base will depend on his abstinence from cocaine.

Jordan S. Dubow, MD, Samuel Singer, MD, Alan Z. Segal, MD, New York, NY

Author contributions: Jordan S. Dubow: involved in conceptualization of paper and drafting the manuscript. Samuel Singer: involved in revising the manuscript. Alan Z. Segal: involved in revising the manuscript.

Disclosure: Dr. Dubow and Dr. Singer report no disclosures. Dr. Segal serves on the speakers' bureau for Boehringer Ingelheim. Address correspondence and reprint requests to Dr. Jordan Dubow, Department of Neurology and Neurosciences, Weil Cornell Medical College, 525 East 68th Street, F610, New York, NY 10065; jsd9001@nyp.org 


\section{Neurology}

\section{Rhomboencephalitis due to cocaine-induced bony erosion of skull base Jordan S. Dubow, Samuel Singer and Alan Z. Segal}

Neurology 2011;77;1313

DOI 10.1212/WNL.0b013e318230209a

This information is current as of September 26, 2011

\section{Updated Information \&} Services

\section{Subspecialty Collections}

Permissions \& Licensing

\section{Reprints}

including high resolution figures, can be found at: http://n.neurology.org/content/77/13/1313.full

This article, along with others on similar topics, appears in the following collection(s):

\section{Cocaine}

http://n.neurology.org/cgi/collection/cocaine

Encephalitis

http://n.neurology.org/cgi/collection/encephalitis

MRI

http://n.neurology.org/cgi/collection/mri

Information about reproducing this article in parts (figures,tables) or in its entirety can be found online at:

http://www.neurology.org/about/about_the_journal\#permissions

Information about ordering reprints can be found online:

http://n.neurology.org/subscribers/advertise

Neurology ${ }^{\circledR}$ is the official journal of the American Academy of Neurology. Published continuously since 1951, it is now a weekly with 48 issues per year. Copyright Copyright $@ 2011$ by AAN Enterprises, Inc.. All rights reserved. Print ISSN: 0028-3878. Online ISSN: 1526-632X.

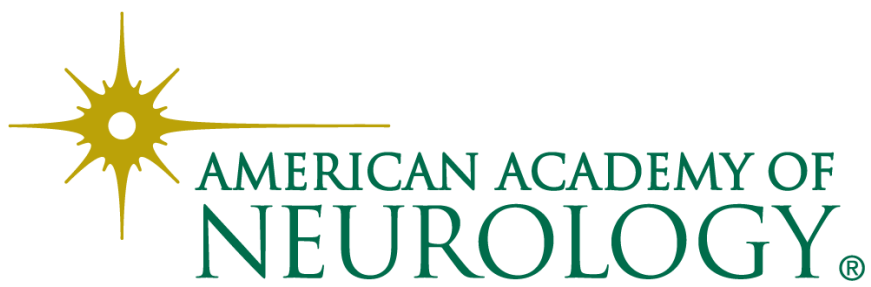

